\title{
AZD5153 Inhibits Prostate Cancer Cell Growth in Vitro and in Vivo
}

\author{
Gang Shen Jianchun Chen Yongqiang Zhou Zhenfan Wang Zheng Ma \\ Chen Xu Minjun Jiang
}

Department of Urology, Wujiang Hospital Affiliated to Nantong University, Wujiang District, Suzhou, China

\author{
Key Words \\ Prostate cancer • BRD4 • AZD5153 • AKT • Chemosensitization
}

\begin{abstract}
Backgrounds/Aims: Bromodomain-containing protein 4 (BRD4) overexpression participates in prostate cancer progression by enhancing the transcriptional activity and expression of several key oncogenes. AZD5153 is a novel BRD4 inhibitor. Methods: Prostate cancer cells were treated with AZD5153. Cell survival was tested by MTT assay and clonogenicity assay. Cell proliferation was tested by $\left[\mathrm{H}^{3}\right]$ DNA incorporation assay. Cell apoptosis was tested by caspase-3/-9 activity assay, Histone DNA ELISA assay, Annexin V FACS assay and TUNEL staining assay. Cell cycle progression was tested by propidium iodide (PI) FACS assay. Signaling was tested by Western blotting assay. The nude mice PC-3 xenograft model was applied to test AZD5153's activity in vivo. Results: AZD5153 inhibited proliferation and survival of established and primary prostate cancer cells. AZD5153 induced apoptosis activation and cell cycle arrest in prostate cancer cells. AZD5153 was non-cytotoxic to the prostate epithelial cells. AZD5153 downregulated BRD4 targets (cyclin D1, Myc, Bcl-2, FOSL1 and CDK4) in PC-3 and primary prostate cancer cells. Further studies show that AKT could be the primary resistance factor of AZD5153. Pharmacological inhibition or genetic depletion of AKT induced BRD4 downregulation, sensitizing AZD5153-induced cytotoxicity in PC-3 cells. In vivo, AZD5153 oral administration inhibited PC-3 xenograft tumor growth in nude mice. Its anti-tumor activity was further enhanced with co-treatment of the AKT specific inhibitor MK-2206. Conclusion: Together, our results indicate a promising therapeutic value of the novel BRD4 inhibitor AZD5153 against prostate cancer cells.
\end{abstract}

\section{Introduction}

(C) 2018 The Author(s) Published by S. Karger AG, Basel

Molecularly-targeted therapy is important for prostate cancer treatment [1-4]. Bromodomain and extraterminal (BET) family proteins have four members, including bromodomain-containing protein (BRD) 2, BRD3, BRD4 and testis-specific isoform BRDT $[5,6]$. BET proteins are transcriptional co-activators. They regulate a number of key cellular 
behaviors, including cell cycle progression, cell proliferation, apoptosis-resistance, migration and invasion $[5,6]$. BET proteins are often overexpressed in human cancers, correlated with cancer initiation, carcinogenesis and progression $[5,6]$. BET inhibitors, including JQ1 and CPI203, have demonstrated promising anti-cancer efficiency in preclinical cancer studies and early clinical trials $[5,6]$.

BRD4 is the most abundant BET family protein [7-10]. It binds to acetylated-histones, acting as a key epigenetic regulator $[7-9,11]$. BRD4 helps to maintain the normal chromatin structure in the daughter cells [7-9]. BRD4 recruits P-TEFb (the positive transcription elongation factor $b$ ) and the RNA polymerase II, both are essential for transcription elongation [9]. BRD4 targets are mostly key oncogenes, including Bcl-2 [12, 13], Myc [11, 14, 15] and cyclin D1 $[16,17]$. Recent studies have proposed BRD4 as a potential therapeutic target of prostate cancer [18-20]. Recent studies have developed a novel, potent and specific BRD4 inhibitor, AZD5153 [21-23]. Unlike other BRD4 inhibitors, AZD5153 is a bivalent BRD4 inhibitor targeting two bromodomains of BRD4 [22]. It displaces BRD4 from chromatin at relatively lower concentration [22]. It's activity against human prostate cancer cells is tested here.

\section{Materials and Methods}

\section{Chemicals and reagents}

AZD5153 was purchased from Medkoo Bioscience (Beijing, China). The antibodies were all provided by the Cell Signaling Tech (Beverly, MA). The AKT inhibitor MK-2206 was purchased from Sigma (Shanghai, China). The AKT inhibitor AKTi-1/2 [24, 25], the BRD4 inhibitors (JQ1 and CPI203) were obtained from Selleck (Shanghai, China).

\section{Cell lines}

Human prostate cancer cell lines, PC-3 and LNCaP, were purchased the iBS cell bank of Fudan University (Shanghai, China). Cells were cultured as monolayer in RPMI-1640 with 10\% FBS (fetal bovine serum). RWPE1, the non-transformed prostate epithelial cell line, was provided by Dr. Shuo [26]. RWPE1 cells were cultured in Defined Keratinocyte-SFM medium supplemented with described growth factors [26]. The reagents for cell culture were all obtained from Hyclone (Suzhou, China).

\section{Primary culture of human cells}

One patient administrated at the first-affiliated hospital of Soochow University was enrolled in this study. The written-informed patient, male, 52-year old, didn't receive prior chemical, hormonal, or radiation therapy before surgery (see our previous study [27]). The prostate cancer tissues and surrounding epithelial tissues were separated carefully. Tissues were minced, digested, and pipetted to disperse clumps [27]. Cells cultured on collagen-coated tissue-culture plates (BD Biosciences, Suzhou, China) in the described medium [26]. Primary human cells at passage 3-10 were utilized for further experiments, with approval by the ethics committee of Nantong University.

\section{MTT assay}

As described [27], methyl thiazolyl tetrazolium (MTT) assay was performed to test cell survival. MTT was dissolved in DMSO. MTT optical density (OD) at $570 \mathrm{~nm}$ was recorded.

\section{Clonogenicity assay}

Prostate cancer cells $\left(5 \times 10^{5}\right.$ per well $)$ with the indicated treatment were trypsinized and re-suspended in agarose-containing medium. Cells were then plated on the top of six-well plates. AZD5153-containing medium was renewed every two days for a total of 10 days. Afterwards, the colonies were counted. 


\section{Cellular Physiology Cell Physiol Biochem 2018;50:798-809 \\ \begin{tabular}{ll|l}
\cline { 2 - 3 } aOI: 10.1159/000494244 & $\begin{array}{l}\text { O } 2018 \text { The Author(s). Published by S. Karger AG, Basel } \\
\text { www.karger.com/cpb }\end{array}$
\end{tabular}}

Shen et al.: AZD5153 Inhibits Prostate Cancer Cell Growth

Western blotting assay

The lysis buffer (Biyuntian, Suzhou, China) was added to cultured cells $[28,29]$. Total cellular lysates were resolved by SDS-PAGE gels, and then transferred onto the PVDF membrane. The blot was incubated with PBST with $10 \%$ non-fat dry milk and desired primary/secondary antibodies. The enhanced chemiluminescence (ECL) method was applied to detect the immuno-reactive bands. Band intensity was quantified by the ImageJ software (NIH).

Caspase-3/-9 activity assay

Twenty $\mu \mathrm{g}$ of cytosolic extracts were mixed with the caspase assay buffer [26] and the caspase-3 substrate Ac-DEVD-AFC $(15 \mu \mathrm{g} / \mathrm{mL})$ or the caspase-9 substrate Ac-LEHD-AFC $(15 \mu \mathrm{g} / \mathrm{mL})$ (Calbiochem, Darmstadt, Germany). After incubation, the amount of released AFC was tested by the spectrofluorometer (Thermo-Labsystems, Helsinki, Finland) with excitation of $380 \mathrm{~nm}$ and emission wavelength of $460 \mathrm{~nm}$.

Annexin V assay

Briefly, cells with the applied treatment were harvested, washed, and incubated with Annexin V and propidium iodide (PI). Afterwards, cells were analyzed by fluorescent-activated cell sorting (FACS) on a FACSCalibur machine (BD Biosciences). Percentage of Annexin V positive cells was recorded .

Histone DNA apoptosis ELISA assay

The Histone-DNA ELISA assay detects apoptotic cell death by quantifying cytoplasmic histoneassociated DNA fragments [26]. The assay was performed with the instruction from the manufacturer (Roche, Shanghai, China). Histone-DNA ELISA OD at $450 \mathrm{~nm}$ was recorded.

TUNEL assay

TUNEL (Terminal deoxynucleotidyl transferase dUTP nick end labeling) In Situ Cell Death Detection Kit (Roche, Shanghai, China) was utilized to quantify cell apoptosis. The percentage of apoptotic cells was determined by the TUNEL percentage (TUNEL/Hoechst $\times 100 \%$ ). At least 100 cells per preparation in five random views were counted.

Cell cycle analysis

After the treatment, cells were labeled with PI $(10 \mu \mathrm{M})$, analyzed on a FACSCalibur machine (BD Biosciences). Cell cycle percentages were recorded.

Quantitative reverse transcriptase real-time polymerase chain reaction (qRT-PCR) assay

Total cellular RNA was extracted by the TRIzol reagents [2]. The First-Strand Synthesis Kit (SABiosciences, Frederick, MD) was utilized for cDNA synthesis. qRT-PCR was performed in Quant studio 3 (Applied Biosystems, Foster City, CA) via the SYBR GREEN kit (TaKaRa, Japan). The $2^{-\Delta \Delta C t}$ method was applied to quantify BRD4 $m R N A$ using GAPDH as the internal control. The mRNA primers for BRD4: 5'ACCTCCAACCCTAACAAGCC-3' and 5'-TTTCCATAGTGTCTTGAGCACC-3' [30], the mRNA primers for GAPDH: 5'-GCACCGTCAAGGCTGAGAAC-3' and 5'-TGGTGAAGACGCCAGTGGA-3' [30] were synthesized by Genechem (Shanghai, China).

\section{AKT1 ShRNA}

AKT1 shRNA lentiviral particles (Santa Cruz Biotech, sc-29195-V) were added to PC-3 cells for 12 hours. Afterwards, puromycin $(10 \mu \mathrm{g} / \mathrm{mL}$, Sigma) was added to select stable cells. AKT1 knockdown in stable cells was verified by Western blotting assay. Control cells were transfected with lentiviral scramble control shRNA (Genechem).

\section{CRISPR/Cas9 knockout of AKT1}

The lentiCRISPR plasmid with the AKT1 CRISPR/Cas9 KO Plasmid, provided by Genepharm (Shanghai, China), was transfected to PC-3 cells. Afterwards, puromycin $(10 \mu \mathrm{g} / \mathrm{mL}$, Sigma) was added to select stable cells. AKT1 knockout in the stable cells was verified by Western blotting assay. 
Shen et al.: AZD5153 Inhibits Prostate Cancer Cell Growth

Xenograft assay

Male nude mice (6-8 weeks old, 17-19 g weight) were provided by the experimental animal center of Soochow University (Suzhou, China). Mice were maintained in accordance with Institutional Animal Care Use Committee guidelines. PC- 3 cells $\left(3 \times 10^{6}\right.$ cells per mouse, dissolved in Matrigel, $1: 1$ ratio, in $0.1 \mathrm{~mL}$ total volume) were injected subcutaneously (s.c.) on the right flanks. Four weeks post tumor implantation, the volume of each tumor was close to $100 \mathrm{~mm}^{3}$. Mice were then randomly assigned into four groups. Tumor volumes, mice body weights and tumor weights were determined as described [27].

\section{Statistical analysis}

Results were expressed as the mean \pm standard deviation (SD). Ordinary one-way ANOVA test was employed for comparison between groups. Multiple comparisons were performed using Tukey's honestly significant difference procedure. To determine significance between two treatment groups, a two-tailed unpaired t test was applied. A $P$ value $<0.05$ was considered statistically different.

\section{Results}

\section{AZD5153 inhibits prostate cancer cell survival and proliferation}

First, PC-3 pancreatic cancer cells [31] were treated with applied concentration of AZD5153 (1-1000 nM). MTT assay results in Fig. 1A demonstrate that AZD5153 dosedependently inhibited PC-3 cell survival, causing significant MTT OD reduction (Fig. 1A). The anti-survival effect by AZD5153 was also time-dependent (Fig. 1A). At least 48 hours

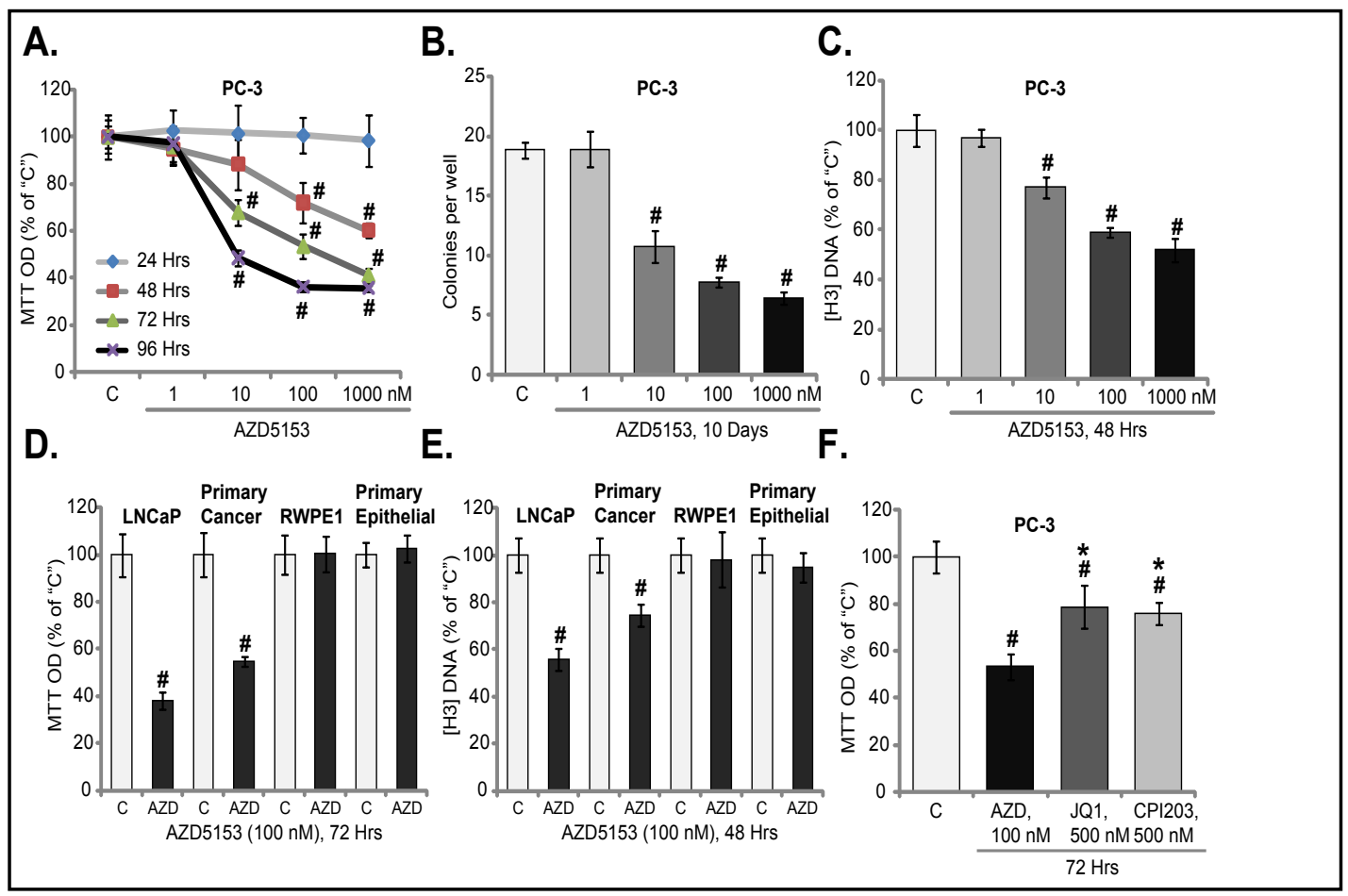

Fig. 1. AZD5153 inhibits prostate cancer cell survival and proliferation. The established (LC-3 and LNCaP lines) or the primary human (patient-derived) prostate cancer cells, the prostate epithelial RWPE1 cells or the primary human (patient-derived) prostate epithelial cells were cultured in complete medium, and cells were treated with applied concentration of AZD5153 (A-F), JQ1 (500 nM) (F) or CPI203 (500 nM) (F) for indicated time, cell survival was tested MTT assay (A, D and F) and clonogenicity assay (B); Cell proliferation was tested by the $\left[\mathrm{H}^{3}\right]$ DNA incorporation assay ( $\mathrm{C}$ and $\mathrm{E}$ ). "C" stands for cells without treatment. For each assay, $\mathrm{n}=5$. Data are mean \pm SD. ${ }^{*} \mathrm{P}<0.05$ vs. "C" cells. $* \mathrm{P}<0.05$ vs. AZD5153 treatment. Experiments in this Fig. were repeated four times, and similar results were observed. 
were required for AZD5153 to achieve significant activity (Fig. 1A). AZD5153's IC-50 (the concentration using $50 \%$ inhibition of cell survival) was close to $100 \mathrm{nM}$ at 72 hours and around $10 \mathrm{nM}$ at 96 hours (Fig. 1A). Clonogenicity assay was performed to test cell survival as well. Results in Fig. 1B show that the number of viable PC-3 cell colonies was significantly decreased after AZD5153 (10-1000 nM) treatment. To test cell proliferation, [H $\mathrm{H}^{3}$ ] DNA incorporation assay [32] was performed, results show that AZD5153 dose-dependently inhibited the amount of incorporated $\left[\mathrm{H}^{3}\right]$ DNA in PC-3 cells (Fig. 1C), suggesting that AZD5153 inhibited PC-3 cell proliferation.

Next, we tested the potential effect of AZD5153 on other prostate cancer cells. In established (LNCaP cell line) and primary (patient-derived) human prostate cancer cells, treatment with $100 \mathrm{nM}$ of AZD5153 significantly decreased cell viability (MTT OD, Fig. 1D) and $\left[\mathrm{H}^{3}\right]$ DNA incorporation (Fig. 1E). RWPE1, the non-transformed prostate epithelial cells [26] and the primary cultured prostate epithelial cells were treated with AZD5153 as well. By performing MTT assay and $\left[\mathrm{H}^{3}\right]$ DNA incorporation assay, we show that AZD5153 failed to affect survival (Fig. 1D) and proliferation (Fig. 1E) of epithelial cells. Significantly, $100 \mathrm{nM}$ of

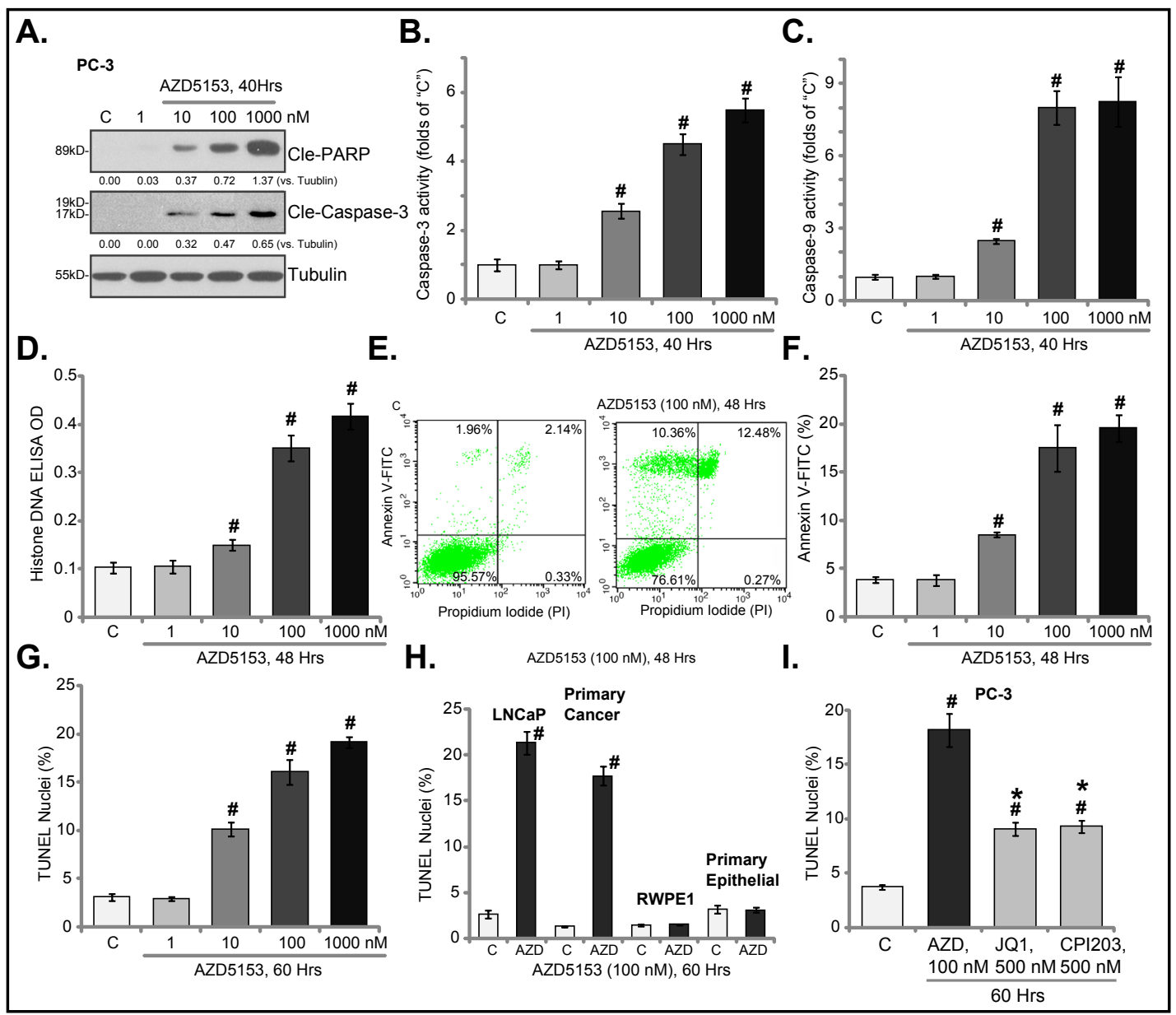

Fig. 2. AZD5153 induces apoptosis activation in prostate cancer cells. The established (LC-3 and LNCaP lines) or the primary human prostate cancer cells, the prostate epithelial RWPE1 cells or the primary human prostate epithelial cells were cultured in complete medium, and cells were treated with applied concentration of AZD5153 (A-I), JQ1 (500 nM) (I) or CPI203 (500 nM) (I) for indicated time, cell apoptosis was tested by the assays mentioned in the text. Cleaved-Caspase- 3 and cleaved-PARP expression were quantified (A). "C" stands for cells without treatment. For each assay, $\mathrm{n}=5$. Data are mean $\pm \mathrm{SD}$. " $\mathrm{P}<0.05$ vs. "C" cells. * $\mathrm{P}<0.05$ vs. AZD5153 treatment (I). Experiments in this Fig. were repeated four times, and similar results were observed. 
AZD5153 was more potent in inhibiting PC-3 cell survival than higher concentration of other BRD4 inhibitors, including JQ1 (500 nM) [16, 33] and CPI203 (500 nM) [34] (Fig. 1F). These results demonstrate that AZD5153 inhibits prostate cancer cell survival and proliferation in vitro.

\section{AZD5153 induces apoptosis activation in prostate cancer cells}

The potential effect of AZD5153 on cell apoptosis was tested. Western blotting assay results in Fig. 2A demonstrate that AZD5153 dose-dependently induced cleavages of caspae-3 and its substrate poly (ADP-ribose) polymerase (PARP) in PC-3 cells. Activities of caspase-3 (Fig. 2B) and caspase-9 (Fig. 2C) were significantly increased as well, followed by the increased content of Histone-bound DNA (Fig. 2D). Additionally, the percentage of PC-3 cells with positive Annexin V-positive staining ("apoptotic cells") was increased after AZD5153 treatment (Fig. 2E and F).

Further studies show that 10-1000 nM of AZD5153 increased the percentage of PC-3 cells with TUNEL staining (Fig. 2G). AZD5153-induced apoptosis activation was dosedependent (Fig. 2A-G). TUNEL staining assay results in Fig. 2H suggest that AZD5153 (100 $\mathrm{nM}$ ) induced apoptosis in LNCaP and primary human prostate cancer cells. Conversely, after AZD5153 treatment, TUNEL ratio was unchanged in RWPE1 and primary prostate epithelial cells (Fig. 2H). Significantly, TUNEL assay results in Fig. 2I demonstrate that AZD5153 (100 $\mathrm{nM}$ ) was more efficient in inducing PC-3 cell apoptosis than JQ-1 and CPI203 (at $500 \mathrm{nM}$ ). Together, AZD5153 induces apoptosis activation in prostate cancer cells.

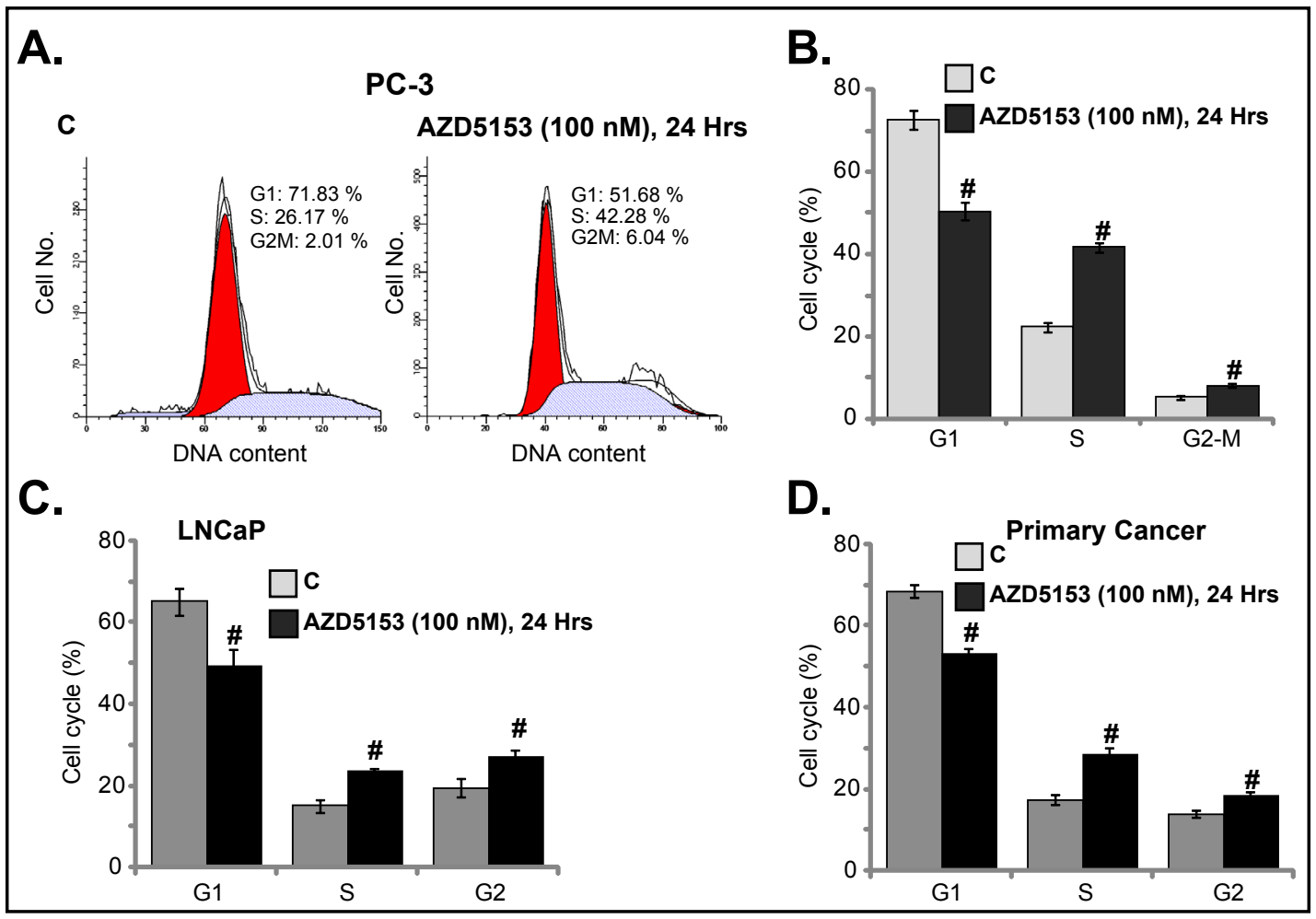

Fig. 3. AZD5153 induces cell cycle arrest in prostate cancer cells. PC-3 cells, LNCaP cells and primary human prostate cancer cells ("Primary Cancer") were cultured in complete medium, and cells were treated with $100 \mathrm{nM}$ of AZD5153 for 24 hours, cell cycle distribution was tested by the PI-FACS assay, representative FACS images were shown (A) and data were quantified (B-D). "C" stands for cells without treatment. For each assay, $n=5$. Data are mean $\pm S D$. ${ }^{\#} P<0.05$ vs. "C" cells. Experiments in this Fig. were repeated four times, and similar results were observed. 


\section{AZD5153 induces cell cycle arrest in prostate cancer cells}

As discussed, BRD4 regulates activation of P-TEFb and RNA polymerase II, both are essential for cell cycle progression [9]. PI FACS assay results in Fig. 3A demonstrate that AZD5153 (100 nM, 24 hours) significantly decreased G1-phase PC-3 cells, yet increasing Sand G2-M phase cells. Results in Fig. 3B confirm that AZD5153-induced cell cycle arrest was significant. The similar results were also observed in AZD5153-treated LNCaP cells (Fig. 3C) and primary human prostate cancer cells (Fig. 3D). Thus, AZD5153 induces cell cycle arrest in prostate cancer cells.

\section{AZD5153 downregulates BRD4 targets in prostate cancer cells}

BRD4 is required for the expression of several key oncogenes [12, 13, 15, 35, 36]. Western blotting assay results show that treatment with AZD5153 (100 nM, 24 hours) induced downregulation of multiple BRD4 targets, including cyclin D1, Myc and Bcl-2 (Fig. 4A and B) as well as FOSL1 and CDK4 (Fig. 4A and B) in PC-3 cells. BRD4 protein expression and AKT expression/activation were not affected by AZD5153 (Fig. 4A and C). The similar results were also obtained in the primary human prostate cancer cells, where AZD5153 (100 nM, 24 hours) efficiently downregulated the BRD4 targets (Fig. 4D and E), while leaving BRD4 expression and AKT unaffected (Fig. 4D and F). These results suggest that AZD5153 inhibits BRD4 in prostate cancer cells.

AKT is a primary resistance factor of AZD5153 in prostate cancer cells

One aim of this study is to identify the possible resistance factors of AZD5153. A very recent study by Zhang et al., has implied that AKT activation might be important for the resistance of BRD4 inhibitors [18]. First, two known AKT inhibitors, AKTi-1/2 [24] and MK-2206 [37], were utilized. As shown in Fig. 5A, AKTi-1/2 or MK-2206 blocked phosphorylation of AKT (at Ser-473) and S6K1 (at Thr-389) [38] in PC-3 cells. BRD4 protein

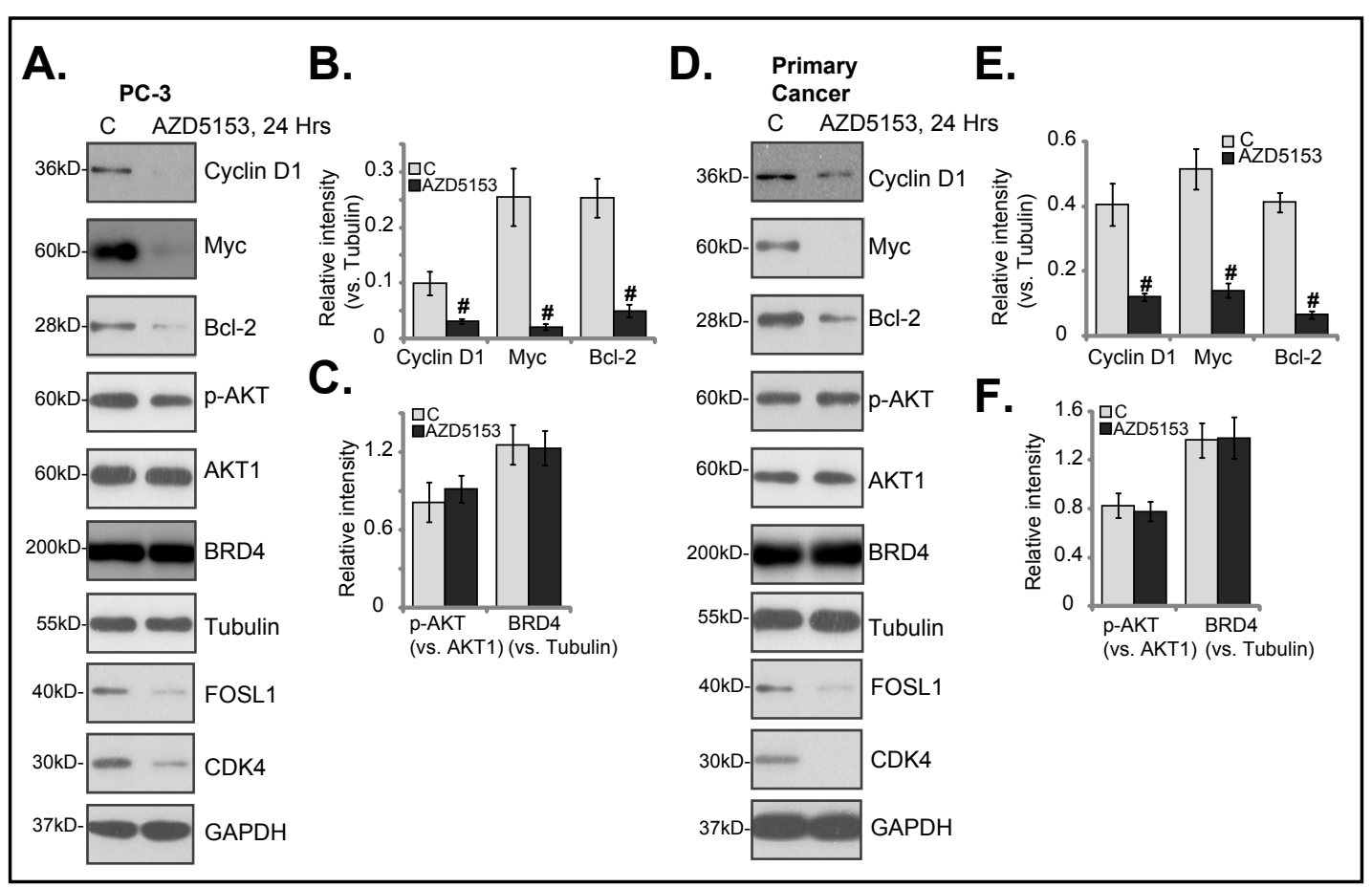

Fig. 4. AZD5153 downregulates BRD4 targets in prostate cancer cells. PC-3 cells (A-C) or the primary human (patient-derived) prostate cancer cells (D-F) were treated with $100 \mathrm{nM}$ of AZD5153 for 24 hours, expression of listed proteins in total cell lysates were tested by the Western blotting assay (A and D); The total gray of each band was quantified, which was normalized to the corresponding loading control (B, C, E and F). "C" stands for cells without treatment. Data are mean \pm SD. ${ }^{\#} \mathrm{P}<0.05$ vs. "C" cells (ANOVA test). Experiments in this Fig. were repeated five times, and similar results were observed. 
and mRNA expression were downregulated as well by the AKT inhibitors (Fig. 5A and B). AZD5153-induced Myc downregulation was however not affected by the AKT inhibitors (Fig. 5A). Significantly, AZD5153 (100 nM)-induced viability reduction (MTT assay, Fig. 5C) and apoptosis activation (TUNEL assay, Fig. 5D) were potentiated by the AKT inhibitors. The CalcuSyn software was applied to calculate Combination Index (CI) using the ChouTalalay method [39]. CI values between AZD5153 and the AKT inhibitors were less than one, indicating a possible synergism. The AKT inhibitors alone only induced minor cytotoxicity in PC-3 cells (Fig. 5C and D).

To exclude the possible off-target toxicities by the AKT inhibitors, genetic strategies were applied. AKT1 shRNA lentivirus were added to PC-3 cells, resulting in significant AKT1 knockdown (Fig. 5E). Further, CRISPR-Cas-9 gene-editing method was utilized to knockout AKT1. AKT1 expression was depleted in stable PC-3 cells with the CRISPR-Cas-9-AKT1 KO plasmid ("AKT1-KO" cells, Fig. 5E). Significantly, expression BRD4 protein and mRNA were reduced by AKT1 shRNA or knockout (Fig. 5E and F). As a result, AZD5153-induced viability reduction (Fig. 5G) and apoptosis (Fig. 5H) were significantly potentiated. The pharmacological and genetic evidence suggest that AKT is a primary resistance factor of AZD5153 in prostate cancer cells.

\section{AZD5153 oral administration inhibits $P C$ - 3 xenograft growth in nude mice}

The potential effect of AZD5153 in vivo was tested. PC-3 cells were inoculated s.c. to the nude mice, treatment was started when tumor volume was around $100 \mathrm{~mm}^{3}$. Tumor growth curve results in Fig. 6A demonstrate that oral administration of AZD5153 (10 mg/kg body weight, daily, for 18 days) significantly inhibited PC-3 xenograft growth. When analyzing estimated daily tumor growth, which was calculated by (volume at Day-35 - volume at Day0)/35, we show again that AZD5153 administration inhibited PC-3 xenograft growth (Fig. 6B). At Day-35, tumors of each group were isolated. AZD5153-treated PC-3 tumors weighted much lower than vehicle control tumors (Fig. 6C). Thus, AZD5153 oral administration inhibited PC-3 xenograft growth in vivo.

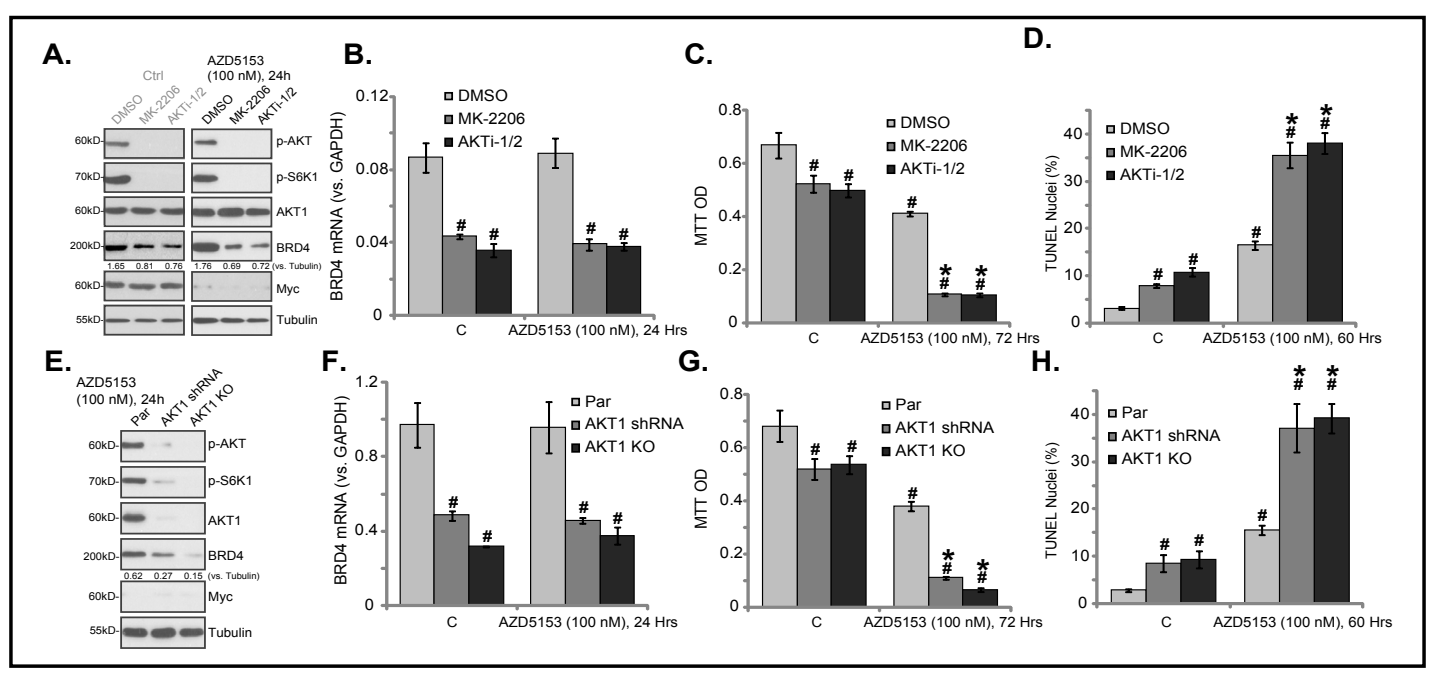

Fig. 5. AKT is a primary resistance factor of AZD5153 in prostate cancer cells. PC-3 cells were treated with $100 \mathrm{nM}$ of AZD5153, with/out AKTi-1/2 (10 $\mu \mathrm{M})$ or MK-2206 $(10 \mu \mathrm{M})$, expression of listed proteins and BRD4 mRNA were shown (A and B); Cell survival (MTT OD, C) and apoptosis (TUNEL-nuclei ratio, D) were tested. The stable PC-3 cells, with AKT1 shRNA or CRISPR-Cas9-AKT1 ("AKT1 KO"), as well as the parental control PC-3 cells ("Par"), were treated with 100 nM of AZD5153, listed proteins and BRD4 mRNA (E and F) were shown. Cell survival $(G)$ and apoptosis $(H)$ were tested. "C" stands for cells without treatment. BRD4 protein expression was quantified (A and E). Data are mean \pm SD. " $\mathrm{P}<0.05$ vs. "C" cells. * $\mathrm{P}<0.05$ vs. AZD5153 treatment in DMSO $(0.1 \%, C$ and D) or "Par" cells (G and H). Experiments in this Fig. were repeated five times, and similar results were observed. 


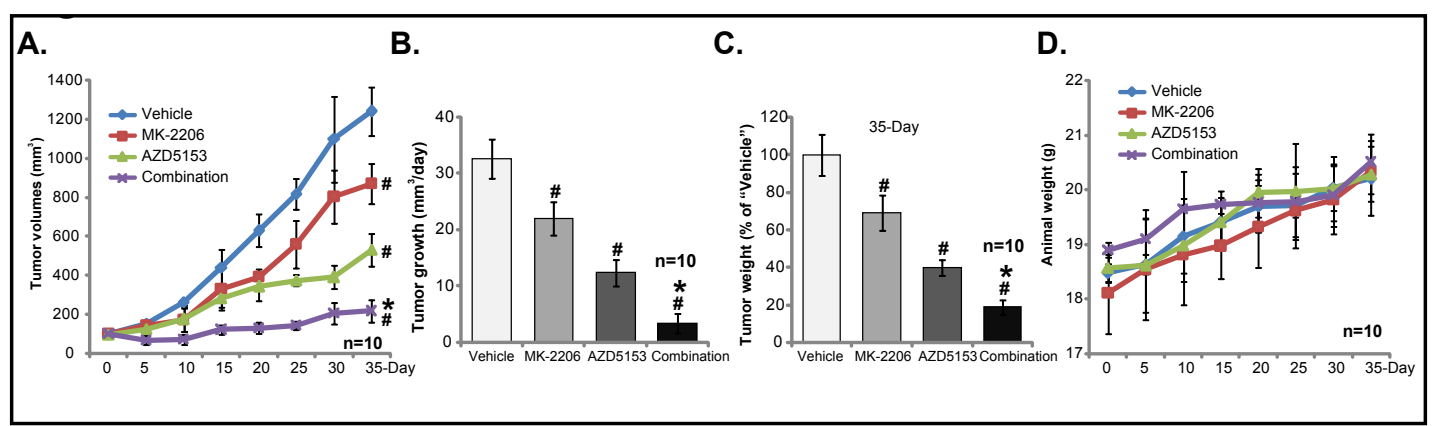

Fig. 6. AZD5153 oral administration inhibits PC-3 xenograft growth in nude mice. PC-3 tumor-bearing nude mice were administrated with AZD5153 (10 mg/kg body weight, daily, p.o.) and/or MK-2206 (5 mg/kg body weight, daily, i.p.) for a total of 18 consecutive days, tumor volume (A) and the mice body weight (D) were recorded every 5 days for a total of 35 days; Estimated daily tumor growth (in $\mathrm{mm}^{3}$ per day) was calculated as described (B). At Day-35, tumors of each group were isolated and weighted (C). For each assay, $\mathrm{n}=10$ mice. Data are mean $\pm \mathrm{SD}$. ${ }^{\#} \mathrm{P}<0.05$ vs. "Vehicle" group (ANOVA test) (A-C). ${ }^{*} \mathrm{P}<0.05$ vs. AZD5153 only treatment (A-C).

PC-3 xenograft-bearing nude mice were also co-administrated with MK-2206. As demonstrated, MK-2206 (5 mg/kgbodyweight, daily,i.p.,for 18 days) co-treatment potentiated AZD5153-induced inhibition on PC-3 xenografts (Fig. 6A-C). MK-2206 administration alone only induced relatively weak tumor inhibition (Fig. 6A-C). The combined activity was more potent than each single treatment (Fig. 6A-C). Experimental animals were well-tolerated to the treatment regimens. We failed to detect any significant body weight differences among the mice (Fig. 6D). Therefore, MK-2206 co-administration sensitizes AZD5153-induced antitumor activity in vivo.

\section{Discussion}

BRD4 regulates transcription and expression of several key oncogenes, including cyclin D1, c-Myc, Bcl-2 and androgen receptor (AR) [15]. Recent studies have proposed BRD4 as an important oncotarget protein for prostate cancer [12-14]. Here, we show that AZD5153, a novel bivalent BRD4 inhibitor [21-23], inhibited survival and proliferation of established (PC-3 and LNCaP lines) and primary human prostate cancer cells. Further, AZD5153 induced apoptosis activation and cell cycle arrest in prostate cancer cells. AZD5153-induced antiprostate cancer cell activity in vitro was more potent than other known BRD4 inhibitors (JQ1 and CPI203). In vivo, AZD5153 oral administration inhibited PC-3 xenograft tumor growth in nude mice.

Resistances to BET inhibitors have been well-documented, the molecular mechanisms of acquired resistance of BRD4 inhibitors are largely unknown until recently. The gene encoding the E3 ubiquitin ligase substrate-binding adaptor speckle-type POZ protein (SPOP) is commonly mutated in human prostate cancers [40]. Cancer-associated SPOP mutations are observed in the meprin and TRAF (Tumor necrosis factor receptor-associated factor) homology (MATH) domain, inhibiting substrate binding [40]. Recent studies have demonstrated that BET proteins, including BRD2, BRD3 and BRD4, are the targets of SPOP [18-20]. Wild-type SPOP binds to the a degron motif in the BET proteins, causing their ubiquitination and proteasomal degradation [18-20]. Conversely, prostate cancer-associated SPOP mutants are not able to bind to BET proteins, which will lead to impaired BET proteins proteasomal degradation [18-20].

A very recent study by Zhang et al., has suggested that activation of AKT-mTORC1 signaling could be a consequence of BRD4 stabilization in human prostate cancer cells [18]. In this study, we show that inhibition of BRD4 by AZD5153 failed to affect AKT-mTORC1 signaling in prostate cancer cells. Rather, AKT activation could be a major resistance factor 


\section{Cellular Physiology Cell Physiol Biochem 2018:50:798-809 \begin{tabular}{l|l|l} 
and Biochemistry & $\begin{array}{l}\text { DOI: 10.1159/000494244 } \\
\text { Published onlIne: } 12 \text { October } 2018\end{array}$ & $\begin{array}{l}\text { @ } 2018 \text { The Author(s). Published by S. Karger AG, Basel } \\
\text { www.karger.com/cpb }\end{array}$ \\
\hline
\end{tabular}}

Shen et al.: AZD5153 Inhibits Prostate Cancer Cell Growth

of AZD5153. AKT activation is important for BRD4 expression in prostate cancer cells. Pharmacological inhibition (MK-2206 or AKTi1-2) or genetic depletion (by shRNA/CRISPRCas9 method) of AKT induced BRD4 downregulation, which significantly potentiated AZD5153-induced cytotoxicity in prostate cancer cells. In vivo, AZD5153-induced anti-tumor activity was sensitized with co-treatment of MK-2206. Thus, AKT inhibition could efficiently sensitize AZD5153 in prostate cancer cells. Further studies will be needed to explore the underlying mechanism of AZD5153 sensitization by AKT inhibition.

\section{Acknowledgements}

This study was supported in part by the Wujiang Hospital Affiliated to Nantong University. All authors carried out the experiments, participated in the design of the study and performed the statistical analysis, participated in its design and coordination and helped to draft the manuscript.

\section{Disclosure Statement}

The authors have no conflict of interest to declare.

\section{References}

1 Shi C, Zhang N, Feng Y, Cao J, Chen X, Liu B: Aspirin Inhibits IKK-beta-mediated Prostate Cancer Cell Invasion by Targeting Matrix Metalloproteinase- 9 and Urokinase-Type Plasminogen Activator. Cell Physiol Biochem 2017;41:1313-1324.

-2 Du Y, Liu XH, Zhu HC, Wang L, Ning JZ, Xiao CC: MiR-543 Promotes Proliferation and EpithelialMesenchymal Transition in Prostate Cancer via Targeting RKIP. Cell Physiol Biochem 2017;41:1135-1146.

-3 Teo MY, O’Shaughnessy MJ, McBride SM, Vargas HA, Scher HI: Drug development for noncastrate prostate cancer in a changed therapeutic landscape. Nat Rev Clin Oncol 2017;10.1038/nrclinonc.2017.160.

4 Saad F: Prostate cancer: 'The prostate' in patients with metastatic prostate cancer: to treat or not to treat? Nat Rev Urol 2017;14:398-399.

5 Shi J, Vakoc CR: The mechanisms behind the therapeutic activity of BET bromodomain inhibition. Mol Cell 2014;54:728-736.

6 Fu LL, Tian M, Li X, Li JJ, Huang J, Ouyang L, Zhang Y, Liu B: Inhibition of BET bromodomains as a therapeutic strategy for cancer drug discovery. Oncotarget 2015;6:5501-5516.

7 Iftner T, Haedicke-Jarboui J, Wu SY, Chiang CM: Involvement of Brd4 in different steps of the papillomavirus life cycle. Virus Res 2017;231:76-82.

8 Bachu M, Dey A, Ozato K: Chromatin Landscape of the IRF Genes and Role of the Epigenetic Reader BRD4. J Interferon Cytokine Res 2016;36:470-475.

-9 Devaiah BN, Singer DS: Two faces of brd4: mitotic bookmark and transcriptional lynchpin. Transcription 2013;4:13-17.

10 Wu X, Liu D, Gao X, Xie F, Tao D, Xiao X, Wang L, Jiang G, Zeng F: Inhibition of BRD4 Suppresses Cell Proliferation and Induces Apoptosis in Renal Cell Carcinoma. Cell Physiol Biochem 2017;41:1947-1956.

-11 Zuber J, Shi J, Wang E, Rappaport AR, Herrmann H, Sison EA, Magoon D, Qi J, Blatt K, Wunderlich M, Taylor MJ, Johns C, Chicas A, Mulloy JC, Kogan SC, Brown P, Valent P, Bradner JE, Lowe SW, Vakoc CR: RNAi screen identifies Brd4 as a therapeutic target in acute myeloid leukaemia. Nature 2011;478:524-528.

12 Wang L, Wu X, Wang R, Yang C, Li Z, Wang C, Zhang F, Yang P: BRD4 inhibition suppresses cell growth, migration and invasion of salivary adenoid cystic carcinoma. Biol Res 2017;50:19.

-13 Li GQ Guo WZ, Zhang Y, Seng JJ, Zhang HP, Ma XX, Zhang G, Li J, Yan B, Tang HW, Li SS, Wang LD, Zhang SJ: Suppression of BRD4 inhibits human hepatocellular carcinoma by repressing MYC and enhancing BIM expression. Oncotarget 2016;7:2462-2474. 


\section{Cellular Physiology Cell Physiol Biochem 2018;50:798-809 \begin{tabular}{ll|l} 
and Biochemistry Published online: 12 October 2018 & $\begin{array}{l}\text { (c) } 2018 \text { The Author(s). Published by S. Karger AG, Basel } \\
\text { www.karger.com/cpb }\end{array}$ \\
\hline
\end{tabular}}

Shen et al.: AZD5153 Inhibits Prostate Cancer Cell Growth

14 Andrews FH, Singh AR, Joshi S, Smith CA, Morales GA, Garlich JR, Durden DL, Kutateladze TG: Dual-activity PI3K-BRD4 inhibitor for the orthogonal inhibition of MYC to block tumor growth and metastasis. Proc Natl Acad Sci U S A 2017;114:E1072-E1080.

15 Ambrosini G, Sawle AD, Musi E, Schwartz GK: BRD4-targeted therapy induces Myc-independent cytotoxicity in Gnaq/11-mutatant uveal melanoma cells. Oncotarget 2015;6:33397-33409.

16 Qiu H, Li J, Clark LH, Jackson AL, Zhang L, Guo H, Kilgore JE, Gehrig PA, Zhou C, Bae-Jump VL: JQ1 suppresses tumor growth via PTEN/PI3K/AKT pathway in endometrial cancer. Oncotarget 2016;7:6680966821.

17 Zhang L, Tong Y, Zhang X, Pan M, Chen S: Arsenic sulfide combined with JQ1, chemotherapy agents, or celecoxib inhibit gastric and colon cancer cell growth. Drug Des Devel Ther 2015;9:5851-5862.

18 Zhang P, Wang D, Zhao Y, Ren S, Gao K, Ye Z, Wang S, Pan CW, Zhu Y, Yan Y, Yang Y, Wu D, He Y, Zhang J, Lu D, Liu X, Yu L, Zhao S, Li Y, Lin D: Intrinsic BET inhibitor resistance in SPOP-mutated prostate cancer is mediated by BET protein stabilization and AKT-mTORC1 activation. Nat Med 2017;23:1055-1062.

19 Janouskova H, El Tekle G, Bellini E, Udeshi ND, Rinaldi A, Ulbricht A, Bernasocchi T, Civenni G, Losa M, Svinkina T, Bielski CM, Kryukov GV, Cascione L, Napoli S, Enchev RI, Mutch DG, Carney ME, Berchuck A, Winterhoff BJN, Broaddus RR et al.: Opposing effects of cancer-type-specific SPOP mutants on BET protein degradation and sensitivity to BET inhibitors. Nat Med 2017;23:1046-1054.

20 Dai X, Gan W, Li X, Wang S, Zhang W, Huang L, Liu S, Zhong Q Guo J, Zhang J, Chen T, Shimizu K, Beca F, Blattner M, Vasudevan D, Buckley DL, Qi J, Buser L, Liu P, Inuzuka H et al.: Prostate cancer-associated SPOP mutations confer resistance to BET inhibitors through stabilization of BRD4. Nat Med 2017;23:1063-1071.

-21 Collins TA, Hattersley MM, Yates J, Clark E, Mondal M, Mettetal JT: Translational Modeling of Drug-Induced Myelosuppression and Effect of Pretreatment Myelosuppression for AZD5153, a Selective BRD4 Inhibitor. CPT Pharmacometrics Syst Pharmacol 2017;6:357-364.

-22 Rhyasen GW, Hattersley MM, Yao Y, Dulak A, Wang W, Petteruti P, Dale IL, Boiko S, Cheung T, Zhang J, Wen S, Castriotta L, Lawson D, Collins M, Bao L, Ahdesmaki MJ, Walker G, O’Connor G, Yeh TC, Rabow AA et al.: AZD5153: A Novel Bivalent BET Bromodomain Inhibitor Highly Active against Hematologic Malignancies. Mol Cancer Ther 2016;15:2563-2574.

-23 Bradbury RH, Callis R, Carr GR, Chen H, Clark E, Feron L, Glossop S, Graham MA, Hattersley M, Jones C, Lamont SG, Ouvry G, Patel A, Patel J, Rabow AA, Roberts CA, Stokes S, Stratton N, Walker GE, Ward L et al.: Optimization of a Series of Bivalent Triazolopyridazine Based Bromodomain and Extraterminal Inhibitors: The Discovery of (3R)-4-[2-[4-[1-(3-Methoxy-[1, 2,4]triazolo [4, 3-b]pyridazin-6-yl)-4-piperidyl]phen oxy] ethyl]-1, 3-dimethyl-piperazin-2-one (AZD5153). J Med Chem 2016;59:7801-7817.

-24 Zhang Q, Yang M, Qu Z, Zhou J, Jiang Q: Autophagy prevention sensitizes AKTi-1/2-induced antihepatocellular carcinoma cell activity in vitro and in vivo. Biochem Biophys Res Commun 2016;480:334340.

25 Puglisi M, Thavasu P, Stewart A, de Bono JS, O’Brien ME, Popat S, Bhosle J, Banerji U: AKT inhibition synergistically enhances growth-inhibitory effects of gefitinib and increases apoptosis in non-small cell lung cancer cell lines. Lung Cancer 2014;85:141-146.

-26 Jiang SJ, Wang S: Dual targeting of mTORC1 and mTORC2 by INK-128 potently inhibits human prostate cancer cell growth in vitro and in vivo. Tumour Biol 2015;36:8177-8184.

-27 Shen G, Jiang M, Pu J: Dual inhibition of BRD4 and PI3K by SF2523 suppresses human prostate cancer cell growth in vitro and in vivo. Biochem Biophys Res Commun 2018;495:567-573.

28 Wang B, Yang X, Sun A, Xu L, Wang S, Lin W, Lai M, Zhu H, Zhou W, Lian Q: Extracellular Signal-Regulated Kinase in Nucleus Accumbens Mediates Propofol Self-Administration in Rats. Neurosci Bull 2016;32:531537.

29 Jiang F, Hua LM, Jiao YL, Ye P, Fu J, Cheng ZJ, Ding G, Ji YH: Activation of mammalian target of rapamycin contributes to pain nociception induced in rats by BmK I, a sodium channel-specific modulator. Neurosci Bull 2014;30:21-32.

-30 He L, Meng D, Zhang SH, Zhang Y, Deng Z, Kong LB: microRNA-608 inhibits human hepatocellular carcinoma cell proliferation via targeting the BET family protein BRD4. Biochem Biophys Res Commun 2018;10.1016/j.bbrc.2018.05.108.

-31 Huang X, Zhu D, Lou Y: A novel anticancer agent, icaritin, induced cell growth inhibition, G1 arrest and mitochondrial transmembrane potential drop in human prostate carcinoma PC-3 cells. Eur J Pharmacol 2007;564:26-36. 


\section{Cellular Physiology Cell Physiol Biochem 2018;50:798-809 \begin{tabular}{l|l} 
DOI: 10.1159/000494244 & O 2018 The Author(s). Published by S. Karger AG, Basel \\
mwwwkarger.com/cpb
\end{tabular}

32 Zhang YM, Zhang ZQ, Liu YY, Zhou X, Shi XH, Jiang Q, Fan DL, Cao C: Requirement of Galphai1/3-Gab1 signaling complex for keratinocyte growth factor-induced PI3K-AKT-mTORC1 activation. J Invest Dermatol 2015;135:181-191.

-33 Korb E, Herre M, Zucker-Scharff I, Darnell RB, Allis CD: BET protein Brd4 activates transcription in neurons and BET inhibitor Jq1 blocks memory in mice. Nat Neurosci 2015;18:1464-1473.

-34 Knudsen KJ, Rehn M, Hasemann MS, Rapin N, Bagger FO, Ohlsson E, Willer A, Frank AK, Sondergaard E, Jendholm J, Thoren L, Lee J, Rak J, Theilgaard-Monch K, Porse BT: ERG promotes the maintenance of hematopoietic stem cells by restricting their differentiation. Genes Dev 2015;29:1915-1929.

-35 Hong SH, Eun JW, Choi SK, Shen Q, Choi WS, Han JW, Nam SW, You JS: Epigenetic reader BRD4 inhibition as a therapeutic strategy to suppress E2F2-cell cycle regulation circuit in liver cancer. Oncotarget 2016;7:32628-32640.

36 Gao X, Wu X, Zhang X, Hua W, Zhang Y, Maimaiti Y, Gao Z: Inhibition of BRD4 suppresses tumor growth and enhances iodine uptake in thyroid cancer. Biochem Biophys Res Commun 2016;469:679-685.

-37 Hirai H, Sootome H, Nakatsuru Y, Miyama K, Taguchi S, Tsujioka K, Ueno Y, Hatch H, Majumder PK, Pan BS, Kotani H: MK-2206, an allosteric Akt inhibitor, enhances antitumor efficacy by standard chemotherapeutic agents or molecular targeted drugs in vitro and in vivo. Mol Cancer Ther 2010;9:1956-1967.

-38 Han C, Wei S, Song Q He F, Xiong X, Wan H, Liu D, Ye F, Liu H, Li L, Xu H, Du X, Kang B, Zeng X: Insulin Stimulates Goose Liver Cell Growth by Activating PI3K-AKT-mTOR Signal Pathway. Cell Physiol Biochem 2016;38:558-570.

39 Chou TC, Talalay P: Quantitative analysis of dose-effect relationships: the combined effects of multiple drugs or enzyme inhibitors. Adv Enzyme Regul 1984;22:27-55.

40 Mani RS: The emerging role of speckle-type POZ protein (SPOP) in cancer development. Drug Discov Today 2014;19:1498-1502. 